\title{
The Effect of Asphyxia on the Pharmacokinetics of Ceftazidime in the Term Newborn
}

\author{
JOHN N. VAN DEN ANKER, BERT J. VAN DER HEIJDEN, WIM C. J. HOP, \\ RIK C. SCHOEMAKER, HENRIETTE M. BROERSE, HERMAN J. NEIJENS, AND
} RONALD DE GROOT

Departments of Pediatrics [J.N.V.D.A., H.M.B., H.J.N., R.D.G.] and Epidemiology and Biostatistics [W.C.J.H.], Erasmus University and University Hospital Rotterdam/Sophia Children's Hospital, Rotterdam, The Netherlands, Center for Human Drug Research [R.C.S.], Leiden, The Netherlands, and Department of Pediatrics [B.J.V.D.H.], Juliana Children's Hospital, The Hague, The Netherlands

\section{ABSTRACT}

The multiple-dose pharmacokinetics of ceftazidime (CAZ) (administered twice daily in a $50 \mathrm{mg} / \mathrm{kg}$ of body weight i.v. dose) were studied in 10 severely asphyxiated term infants with suspected septicemia on $\mathrm{d} 3$ of life. Nine term infants with suspected septicemia but without asphyxia served as controls. Blood samples were collected from an arterial catheter at $0,0.5,1,2,4,8$, and $12 \mathrm{~h}$ after an i.v. bolus injection. A high performance liquid chromatography method was used to determine CAZ concentrations from serum. CAZ pharmacokinetics followed a onecompartment open model. The GFRs of all infants were simultaneously studied by means of the 24-h continuous inulin infusion technique. Elimination serum half-life $(5.86 \pm 1.13 \mathrm{~h}$ versus $3.85 \pm 0.40 \mathrm{~h}$ ) and serum trough concentrations ( $46 \pm 14$ $\mathrm{mg} / \mathrm{L}$ versus $23 \pm 7 \mathrm{mg} / \mathrm{L}$ ) of CAZ were significantly ( $p<$ 0.001 ) increased in the asphyxiated newborn, whereas total body clearance of CAZ $(128.4 \pm 25.1 \mathrm{~mL} / \mathrm{h}$ versus $205.7 \pm 55.4$
$\mathrm{mL} / \mathrm{h}), \mathrm{CAZ}$ clearance per $\mathrm{kg}(40.9 \pm 6.1 \mathrm{~mL} / \mathrm{h} / \mathrm{kg}$ versus 60.8 $\pm 8.3 \mathrm{~mL} / \mathrm{h} / \mathrm{kg})$, and the GFR expressed in $\mathrm{mL} / \mathrm{min}(3.14 \pm 0.43$ versus $4.73 \pm 0.89)$ were significantly $(p<0.001)$ decreased in the asphyxiated newborn. We conclude that twice daily administration of $50 \mathrm{mg} / \mathrm{kg}$ of body weight CAZ given to asphyxiated term newborns in the first days of life results in significantly higher serum trough levels in comparison with control infants. The impaired CAZ clearance is a result of a significantly decreased GFR. (Pediatr Res 38: 808-811, 1995)

CAZ, ceftazidime

\section{Abbreviations}

$t_{1 / 2}$, elimination serum half-life

$\mathbf{C L}_{\text {in }}$, inulin clearance

$V$, apparent volume of distribution
Perinatal asphyxia is a result of complicated or traumatic deliveries and may exert profound effects on renal and liver function. McCance and Widdowson (1) reported as early as 1954 a reduction in the GFR, a poor urea clearance, and a low urine output in full-term and postmature infants after prolonged and difficult labor. A redistribution of the fetal circulation leading to an increased blood flow to the brain, heart, and adrenals and a concomitantly decreased blood flow to the lungs, intestines, and kidneys is responsible for this asphyxiainduced renal impairment (2). Several drugs such as the $\beta$-lactam antibiotic CAZ are primarily excreted by the kidneys. CAZ, a broad spectrum cephalosporin, is an antibiotic frequently used for the treatment of infectious diseases in newborn infants. The currently recommended dosage for CAZ in term infants is $50-150 \mathrm{mg} / \mathrm{kg}$ of body weight per day in two or

Received December 20, 1994; accepted April 11, 1995.

Manuscript dedicated to Professor H.K.A. Visser in honor of his retirement.

Correspondence: John N. van den Anker, M.D., Sophia Children's Hospital, Dr. Molewaterplein 60, 3015 GJ Rotterdam, The Netherlands.

Supported by a research grant from Glaxo B.V., The Netherlands. three daily doses $(3,4)$. The dosage and dosing interval of CAZ will be influenced by changes in GFR such as those caused by asphyxia. However, pharmacokinetic studies in asphyxiated newborns have not been performed. Hence, recommendations to adjust drug dosages of CAZ are not available. We therefore examined the impact of asphyxia on the disposition characteristics of CAZ in the term newborn.

\section{METHODS}

Patients. Ten term infants with severe asphyxia were included in this study. All infants met the criteria as recently defined by the American College of Obstetricians and Gynecologists and the American Academy of Pediatrics Committees on Maternal-Fetal Medicine and Fetus and Newborn (5). All of the following were present: profound umbilical artery acidemia ( $\mathrm{pH}<7.00$ ), persistence of an Apgar score of 0-3 longer than 5 min, neonatal neurologic sequelae (e.g. seizures, coma, hypotonia), and multiorgan system dysfunction (e.g. cardiovascular, gastrointestinal, hematologic, pulmonary, or renal). Nine 
term infants without asphyxia served as controls. Five of these infants had meconium aspiration syndrome but normal Apgar scores and an umbilical arterial $\mathrm{pH}$ above 7.15, and four had transient tachypnea of the newborn. Infants receiving nephrotoxic or inotropic drugs were excluded. All infants had an indwelling radial artery catheter. The study protocol was approved by the Medical Ethical Committee of the University Hospital Rotterdam. Patients were enrolled only after informed consent was obtained from the parents. All infants received because of suspected septicemia directly from birth $50 \mathrm{mg} / \mathrm{kg}$ of body weight CAZ and $50 \mathrm{mg} / \mathrm{kg}$ of body weight amoxicillin i.v. every $12 \mathrm{~h}$ as a bolus injection. In patients with sterile blood cultures and without a focus of infection the therapy was discontinued after $72 \mathrm{~h}$.

Pharmacokinetic study. The multiple-dose pharmacokinetics of CAZ were studied on $\mathrm{d} 3$ after birth because antibiotic treatment was stopped after $72 \mathrm{~h}$ in infants with sterile blood cultures. Blood samples were taken from indwelling arterial lines before an i.v. bolus injection of CAZ $(t=0)$ and at 0.5 , $1,2,4,8$, and $12 \mathrm{~h}$ after the administration. These sampling times were selected based on the known disposition profile for CAZ. Serum samples obtained after centrifugation (Merck type Eppendorf $5414,3000 \times g$ for $1 \mathrm{~min}$ ) were stored at $-70^{\circ} \mathrm{C}$.

Measurement of the GFR. The GFR was measured on $\mathrm{d} 3$ after birth by means of the continuous inulin infusion technique $(6,7)$. A $10 \%$ glucose-inulin solution containing $25 \mathrm{~g}$ of inulin per liter was infused at a rate of $0.6 \mathrm{~mL} / \mathrm{kg} / \mathrm{h}$, beginning at time $(t)$ zero of the pharmacokinetic study. After $24 \mathrm{~h}$, the inulin clearance $\left(\mathrm{CL}_{\text {in }}\right)$ was calculated from the infusion rate $(R)$, the inulin concentration in the infusate $(I)$, and the serum inulin concentration $\left(\mathrm{P}_{\text {in }}\right)$ by the equation $\mathrm{CL}_{\text {in }}=(I \cdot R) / \mathrm{P}_{\text {in }}$. The determination of inulin in serum was performed after acid hydrolysis in $0.3 \mathrm{mmol} / \mathrm{L}$ perchloric acid for $15 \mathrm{~min}$ at $70^{\circ} \mathrm{C}$. The fructose thus formed was measured enzymatically according to Beutler (8).

Ceftazidime assay. Analysis of serum $\mathrm{CAZ}$ concentrations was performed according to the method described by Ayrton (9) with minor modifications. HPLC-grade acetonitrile was purchased from Rathburn (Walkerburn, Scotland). The other chemicals were purchased from Aldrich-Chemie (Steinheim, Germany). All chemicals applied were of the highest grade commercially available. Chromatographic analysis was performed with a glass-prepacked $\mathrm{C}_{18}$ column (100 by $8 \mathrm{~mm}$, Resolve Radial Pak, Waters, Rochester, $\mathrm{MN}$ ) combined with a guard column. A Waters model 6000 chromatography pump was used to deliver the eluent: $4.8 \%$ ( $\mathrm{vol} / \mathrm{vol}$ ) acetonitrile, $13.5 \%$ methanol in $20 \mathrm{mM}$ sodium acetate buffer $(\mathrm{pH} 3.6)$ at a flow rate of $2 \mathrm{~mL} / \mathrm{min}$. The separations were carried out at room temperature. The eluate was monitored with two Waters absorbance detectors (model 440/wavelength of $254 \mathrm{~nm}$ and model 484/wavelength $265 \mathrm{~nm}$.

To a $50-\mu \mathrm{l}$ aliquot of the serum sample, an equal volume of $6 \%$ (vol/vol) perchloric acid containing $50 \mathrm{mg} / \mathrm{L}$ cephaloridine as an internal standard was added. Samples were centrifuged at $1500 \mathrm{~g}$ for $5 \mathrm{~min}$ (Eppendorf centrifuge 5412). Subsequently $25 \mu \mathrm{L}$ were transferred by an automatic sample injector (WISP $710 \mathrm{~B}$; Waters) to the column.
A calibration curve was made by dissolving 4, 12, 25, 50, 100, 200, and $400 \mu \mathrm{g} \mathrm{CAZ} \mathrm{per} \mathrm{mL}$ in serum. These spiked standard samples were processed according to the procedure mentioned above. A linear calibration curve was obtained over a range of 4 to $400 \mu \mathrm{g}$ of $\mathrm{CAZ} / \mathrm{mL}$. Spiked samples of the calibration curve underwent the same processing procedure as clinical samples. Hence, clinical samples were directly converted from the calibration curve to actual CAZ concentrations per $\mathrm{mL}$ of serum. The lower limit of detection of CAZ in serum was $0.5 \mathrm{mg} / \mathrm{L}$. The coefficients of interassay variation at different concentrations were less than $7 \%$. The intraassay values were less than $5 \%$. Recovery of $95 \%$ of CAZ, which had been incubated for $24 \mathrm{~h}$ at room temperature, was established.

Pharmacokinetic analysis. Kinetic studies were performed on the 3rd d of life. Kinetic data were described using a one-compartment open model. Visual inspection of individual model fits gave no indication that a model more complex than a one-compartment open model was required. Pharmacokinetic parameters were calculated using the multiple dose equations described by Rowland and Tozer (10). The basic equation used was $C_{t}=\operatorname{dose} / V \times\left(1-r^{N}\right) /(1-r) \times e^{-k t}$. In this equation $C_{t}$ is the serum concentration of CAZ at times $t$ after each dose, $V$ the apparent volume of distribution, $N$ the dose number, $r=$ $e^{-k \tau}$, in which $k$ is the elimination rate constant and $\tau$ the dosing interval. Because doses were given twice daily, the CAZ concentration versus time-curve was assumed attributable to the seventh dose (and the trough level at $t=0$ to the sixth dose). Total body clearance (CL) was calculated with the following equation: $\mathrm{CL}=k \cdot V$. Concentration time plots showed a linear decrease over time and no indication of leveling off. Scatter was evenly distributed on log-scale indicating the need for $1 /(Y \mathrm{cal})^{2}$ weighting. All calculations were carried out using the nonlinear regression module of SPSS/ PC+ V 4.0.1 (SPSS Inc., Chicago, IL), which uses an Levenberg-Marquardt algorithm.

To examine different dosing strategies, based on the assumption that serum concentrations should never drop below 5 $\mathrm{mg} / \mathrm{L}$, dosage recommendations for CAZ were calculated using the following equation:

$$
5<C_{\tau}=\frac{D \times \mathrm{wt}}{V} \times e^{-k \tau}
$$

In this formula $C_{\tau}$ is the serum trough concentration, $D$ the prescribed dose in $\mathrm{mg} / \mathrm{kg}$, wt the weight in $\mathrm{kg}$, $k$ the elimination rate constant, $\tau$ the dosing interval in $\mathrm{h}, V$ the apparent volume of distribution of CAZ.

Statistical analysis. Data given are mean \pm SD unless indicated otherwise. Correlation coefficients are Pearson's. Continuous data were compared using the Mann-Whitney test. $p$ values $\leq 0.05$ (two-tailed) were considered significant. With the numbers studied, differences between groups can be demonstrated $(\alpha=0.05, \beta=0.20)$ if these exceed 1.2 SD.

\section{RESULTS}

The demographic and clinical parameters of all infants (asphyxiated versus nonasphyxiated) are shown in Table 1. None of the infants in both groups had a positive blood culture. 
Table 1. Demographic and clinical parameters of study infants*

\begin{tabular}{lcc}
\hline \multicolumn{1}{c}{ Parameter } & $\begin{array}{c}\text { Asphyxiated } \\
(n=10)\end{array}$ & $\begin{array}{c}\text { Controls } \\
(n=9)\end{array}$ \\
\hline Gestational age (wk) & $392 / 7 \pm 14 / 7$ & $395 / 7 \pm 12 / 7$ \\
Weight (g) & $3057 \pm 371$ & $3367 \pm 531$ \\
Artificial ventilation & $5(50 \%)$ & $4(44 \%)$ \\
Apgar score 5 minutes & $2 \pm 1 \dagger$ & $8 \pm 1$ \\
Convulsions & $10(100 \%) \dagger$ & $0(0 \%)$ \\
Umbilical pH & $6.7 \pm 0.1 \dagger$ & $7.3 \pm 0.1$ \\
\hline
\end{tabular}

$*$ Values are mean $( \pm \mathrm{SD})$ or numbers $(\%)$ of patients.

$\dagger$ Significantly different $(p<0.01)$ from controls.

The pharmacokinetics of $\mathrm{CAZ}$ and the $\mathrm{CL}_{\text {in }}$ are shown in Table 2. Figure 1 demonstrates the serum CAZ concentration (mean $\pm \mathrm{SD}$ ) versus time curve of the asphyxiated and control infants. $\mathrm{CL}_{\mathrm{in}}$ was significantly lower in the asphyxiated newborn $(3.14 \pm 0.43 \mathrm{~mL} / \mathrm{min}$ versus $4.73 \pm 0.89 \mathrm{~mL} / \mathrm{min}, p<$ 0.001). A positive linear relationship $(r=0.87, p<0.001)$ was demonstrated between CAZ clearance and the GFR. In Figure 2 this relation is shown. As there was no significant difference between the separate regression lines of the two groups, the common regression line is depicted with $95 \%$ confidence limits. CAZ clearance was significantly lower in the asphyxiated newborns $(128.4 \pm 25.1 \mathrm{~mL} / \mathrm{h}$ versus $205.7 \pm 55.4 \mathrm{~mL} / \mathrm{h}$, $p<0.001)$. After correction for body weight, CAZ clearance was still significantly lower in the asphyxiated newborns (40.9 $\pm 6.1 \mathrm{~mL} / \mathrm{h} / \mathrm{kg}$ versus $60.8 \pm 8.3 \mathrm{~mL} / \mathrm{h} / \mathrm{kg}, p<0.001)$. The apparent volume of distribution $(V)$ of CAZ did not differ significantly between the groups. After correction for body weight there still was no difference in the $V$ of CAZ between both groups. Consequently the $t_{1 / 2}$ of CAZ was significantly longer in the asphyxiated newborns $(5.86 \pm 1.13 \mathrm{~h}$ versus 3.85 $\pm 0.40 \mathrm{~h}, p<0.001)$. Serum peak levels of CAZ showed no significant difference between both groups. Serum trough levels of CAZ were significantly $(p<0.005)$ higher in the asphyxiated group ( $46 \pm 14 \mathrm{mg} / \mathrm{L})$ in comparison with the control infants $(23 \pm 7 \mathrm{mg} / \mathrm{L})$.

Based on the assumption that serum concentrations should never drop below $5 \mathrm{mg} / \mathrm{L}$, using the equation given in the methods section, dosage recommendations for CAZ were calculated.

Table 2. Pharmacokinetic parameters of ceftazidime and inulin clearances of infants with severe asphyxia and in control infants without asphyxia

\begin{tabular}{lccc}
\hline \multicolumn{1}{c}{ Parameter } & $\begin{array}{c}\text { Asphyxiated } \\
(n=10)\end{array}$ & $\begin{array}{c}\text { Controls } \\
(n=9)\end{array}$ & $p$ value \\
\hline $\mathrm{CL}(\mathrm{ml} / \mathrm{h})$ & $128.4 \pm 25.1$ & $205.7 \pm 55.4$ & $<0.001$ \\
$\mathrm{CL}(\mathrm{ml} / \mathrm{h} / \mathrm{kg})$ & $40.9 \pm 6.1$ & $60.8 \pm 8.3$ & $<0.001$ \\
$V(\mathrm{ml})$ & $1090 \pm 304$ & $1132 \pm 258$ & $\mathrm{NS}$ \\
$V(\mathrm{ml} / \mathrm{kg})$ & $344 \pm 79$ & $336 \pm 46$ & $\mathrm{NS}$ \\
$t_{1 / 2}(\mathrm{~h})$ & $5.86 \pm 1.13$ & $3.85 \pm 0.40$ & $<0.001$ \\
$\mathrm{CL}_{\text {in }}(\mathrm{ml} / \mathrm{h})$ & $188.4 \pm 25.5$ & $284.2 \pm 53.1$ & $<0.001$ \\
$\mathrm{CL}_{\text {in }}(\mathrm{ml} / \mathrm{min})$ & $3.14 \pm 0.43$ & $4.73 \pm 0.89$ & $<0.001$ \\
\hline
\end{tabular}

Values are mean $\pm \mathrm{SD}$. CL, total body clearance; $V$, apparent volume of distribution; $t_{1 / 2}$, elimination serum half-life, $\mathrm{CL}_{\text {in }}$, inulin clearance; NS, not significant.

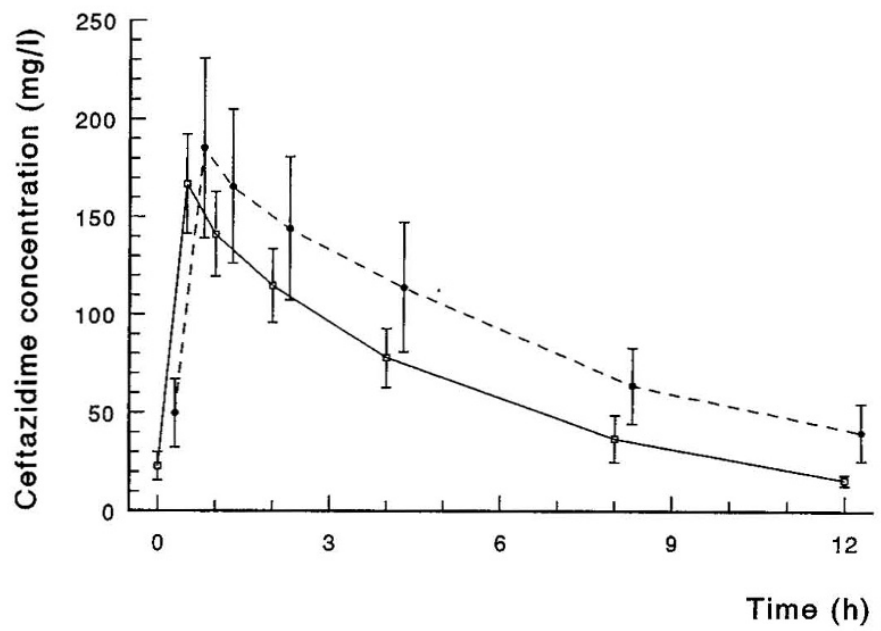

Figure 1. Serum CAZ concentrations (mean $\pm \mathrm{SD}$ ) vs time curve of asphyxiated (dotted line) or control (solid line) groups.

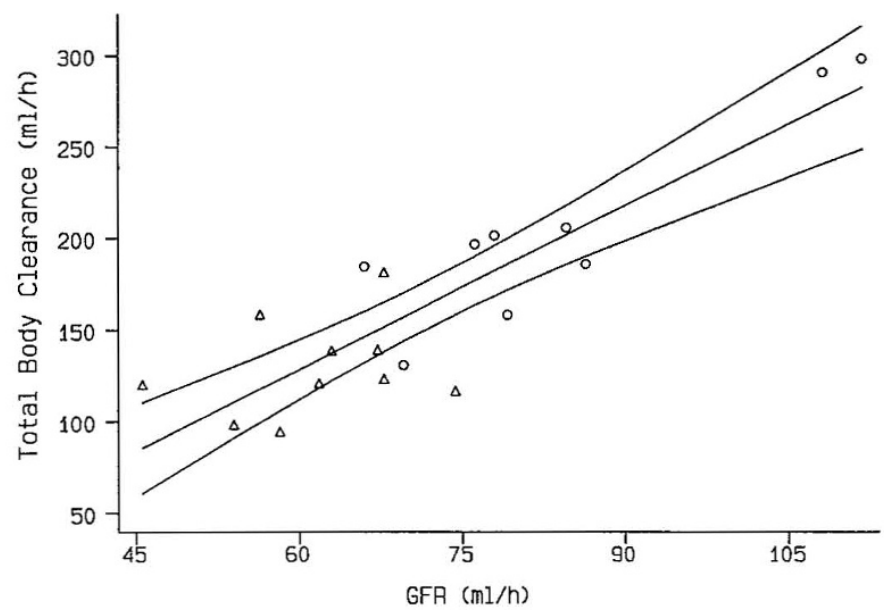

Figure 2. GFR (inulin clearance) expressed in $\mathrm{mL} / \mathrm{h}$ vs total body clearance of CAZ. The curved lines indicate the $95 \%$ confidence limits. The regression line equals: $y=-50.2+3.0 \times$ GFR.

\section{DISCUSSION}

The data presented in this study indicate that asphyxia in term infants results in a significant decrease in the GFR as measured by the $\mathrm{CL}_{\text {in }}$. The positive relationship $(r=0.87, p<$ 0.001 ) between the GFR and the CAZ clearance indicates the important role of the GFR in the clearance of CAZ. The decrease in the GFR results in a significant decrease in the CAZ clearance and a concomitant increase of $t_{1 / 2}$ of CAZ and serum trough levels $(46 \pm 14 \mathrm{mg} / \mathrm{L})$ in the asphyxiated infants. These results indicate that twice daily administration of 50 $\mathrm{mg} / \mathrm{kg} \mathrm{CAZ}$ to term asphyxiated newborns results in high serum concentrations of $\mathrm{CAZ}$ during the entire dosing interval. An optimal dose regimen should result in a high clinical efficacy and a minimal degree of toxicity. To ensure clinical efficacy the serum concentrations of CAZ should be above the minimal inhibitory concentration (MIC) of CAZ for major neonatal pathogens such as Streptococcus agalactiae $\left(\mathrm{MIC}_{90}\right.$ $<0.25 \mathrm{mg} / \mathrm{L})$ and Escherichia coli $\left(\mathrm{MIC}_{90}<0.25 \mathrm{mg} / \mathrm{L}\right)(11$, 12). The serum levels of CAZ in the current study were far above the MICs during the entire dosing interval. Therefore modification of the CAZ dose in the asphyxiated newborn is 
not indicated to improve clinical efficacy. However, $\beta$-lactam antibiotics are all neurotoxic to some extent $(13,14)$. Several factors have been identified or suggested to contribute to the neurotoxicity of the $\beta$-lactam antibiotics: excessive dosage, renal insufficiency, disruption of the blood-brain barrier, preexisting CNS diseases, and competitive inhibition of the transport system that exports $\beta$-lactam antibiotics out of the CNS. In adults CAZ has been reported to cause encephalopathy, hallucinations, confusion, and neuromuscular excitability (15-19). In the rat model, a dose-dependent suppressive effect of $\beta$-lactam antibiotics has been demonstrated on the differentiation and proliferation of oligodendrocytes (20).

Asphyxia neonatorum is associated with an impaired renal function, which will result in high serum levels of CAZ. CSF acidosis and an increased CSF lactate level may lead to an impaired capacity to export $\beta$-lactam antibiotics out of the CNS, resulting in accumulation of the drug inside the CSF. Finally cerebral edema, hypoxia, and ischemia will make the brain more vulnerable for neurotoxicity. In our study we could not detect CAZ-related neurotoxicity because asphyxia in itself was responsible for neurologic sequelae in the immediate neonatal period including seizures, hypotonia, coma, or hypoxic-ischemic encephalopathy. Although no CAZ-related side effects could be demonstrated in this study, the data described above indicate that modification of the dose of CAZ in the asphyxiated newborn should be performed to prevent potential drug-induced neurotoxicity.

We decided to use a model in which a trough level of $5 \mathrm{mg} / \mathrm{L}$ was chosen as the minimum level desired for appropriate bacterial killing of the most important neonatal microorganisms. Two different strategies were used for the calculations. Dosage recommendations were calculated using a fixed dosing interval of $12 \mathrm{~h}$, which resulted in a CAZ dose of $25 \mathrm{mg} / \mathrm{kg}$ every $12 \mathrm{~h}$. Alternatively appropriate dosing could also be achieved by extending the dosing interval to $18 \mathrm{~h}$ using a CAZ dose of $50 \mathrm{mg} / \mathrm{kg}$. We conclude that asphyxia has a significant impact on the disposition characteristics of CAZ in the term newborn and that dosage adjustments of CAZ are indicated in term asphyxiated infants with a decreased GFR. Further studies are needed to examine the impact of asphyxia on the disposi- tion of drugs with extensive renal clearance like CAZ. In addition the impact of asphyxia on the disposition of drugs with extensive nonrenal clearance like theophylline also needs to be investigated.

\section{REFERENCES}

1. McCance RA, Widdowson EM 1954 The influence of events during the last few days in utero on tissue destruction and renal function in the first two days of independent life. Arch Dis Child 29:495-498

2. Reid DL, Parer JT, Williams K 1991 Effects of severe reduction in maternal placental blood flow on blood flow distribution in the sheep fetus. J Dev Physiol 15:183-188

3. Stutman HR, Marks MI 1992 Cephalosporins. In: Yaffe SJ and Aranda JV (eds) Pediatric Pharmacology, 2nd Ed. WB Saunders, Philadelphia, pp 252-261

4. Committee on Infectious Diseases American Academy of Pediatrics 1994 Antibacterial drugs for newborn infants. In: Peter G (ed) 1994 Red Book: Report of the Committee on Infectious Diseases, 23rd Ed. American Academy of Pediatrics, Elk Grove Village, IL, pp 543-545

5. American Academy of Pediatrics, American College of Obstetricians and Gynecologists: Relationship between perinatal factors and neurologic outcome 1992 In: Poland RL, Freeman RK (eds) Guidelines for Perinatal Care, 3rd Ed. American Academy of Pediatrics, Elk Grove Village, IL, pp 221-224

6. Van der Heijden AJ, Grose WFA, Ambagtsheer JJ, Provoost AP, Wolff ED, Sauer PJJ 1988 Glomerular filtration rate in the preterm infant: the relation to gestational and postnatal age. Eur J Pediatr 148:24-28

7. Van den Anker JN, Hop WCJ, De Groot R, Van der Heijden AJ, Broerse HM, Lindemans J, Sauer PJJ 1994 Effects of prenatal exposure to betamethasone and indomethacin on the glomerular filtration rate in the preterm infant. Pediatr Res 36:578-581

8. Beutler H-O 1984 Inulin. In: Bergmeyer HU (ed) Methods of Enzymatic Analysis, Vol VI. Verlag Chemie, Weinheim, Germany, pp 41-45

9. Ayrton J 1981 Assay of ceftazidime in biological fluids using high-pressure liquid chromatography. J Antimicrob Chemother 8:227-231

10. Rowland M, Tozer TN 1989 Amount of drug in the body on accumulation. In: Rowland M and Tozer TN (eds) Clinical Pharmacokinetics: Concepts and Application, 2nd Ed. Lea \& Febiger, Philadelphia, pp 473-475

11. Gentry LO 1985 Antimicrobial activity, pharmacokinetics, therapeutic indications and adverse reactions of ceftazidime. Pharmacotherapy 5:254-267

12. Neu HC 1981 In vitro activity of ceftazidime, a $\beta$-lactamase stable cephalosporin. J Antimicrob Chemother 8:131-134

13. Snavely SR, Hodges GR 1984 The neurotoxicity of antibacterial agents. Ann Intern Med 101:92-104

14. Schliamser SE, Cars O, Norrby SR 1991 Neurotoxicity of beta-lactam antibiotics: predisposing factors and pathogenesis. J Antimicrob Chemother 27:405-425

15. Douglas MA, Quandt CM, Stanley DA 1988 Ceftazidime-induced encephalopathy in a patient with renal impairment. Arch Neurol 45:936-937

16. Al-Zahawi MF, Sprott MS, Hendrick DJ 1988 Hallucinations in association with ceftazidime. BMJ 297:858

17. Geyer J, Hoffler D, Demers HG, Niemeyer R 1988 Cephalosporin-induced encephalopathy in uremic patients. Nephron 48:237

18. Slaker RA, Danielson B 1991 Neurotoxicity associated with ceftazidime therapy in geriatric patients with renal dysfunction. Pharmacotherapy 11:351-352

19. Jackson GD, Berkovic SF 1992 Ceftazidime encephalopathy: absence status and toxic hallucinations. J Neurol Neurosurg Psychiatry 55:333-334

20. Schaad UB, Guenin K, Steffen C, Herschkowitz N 1988 Effects of antimicrobial agents used for therapy of CNS infections on dissociated brain cell cultures. Pediatr Res 24:367-372 